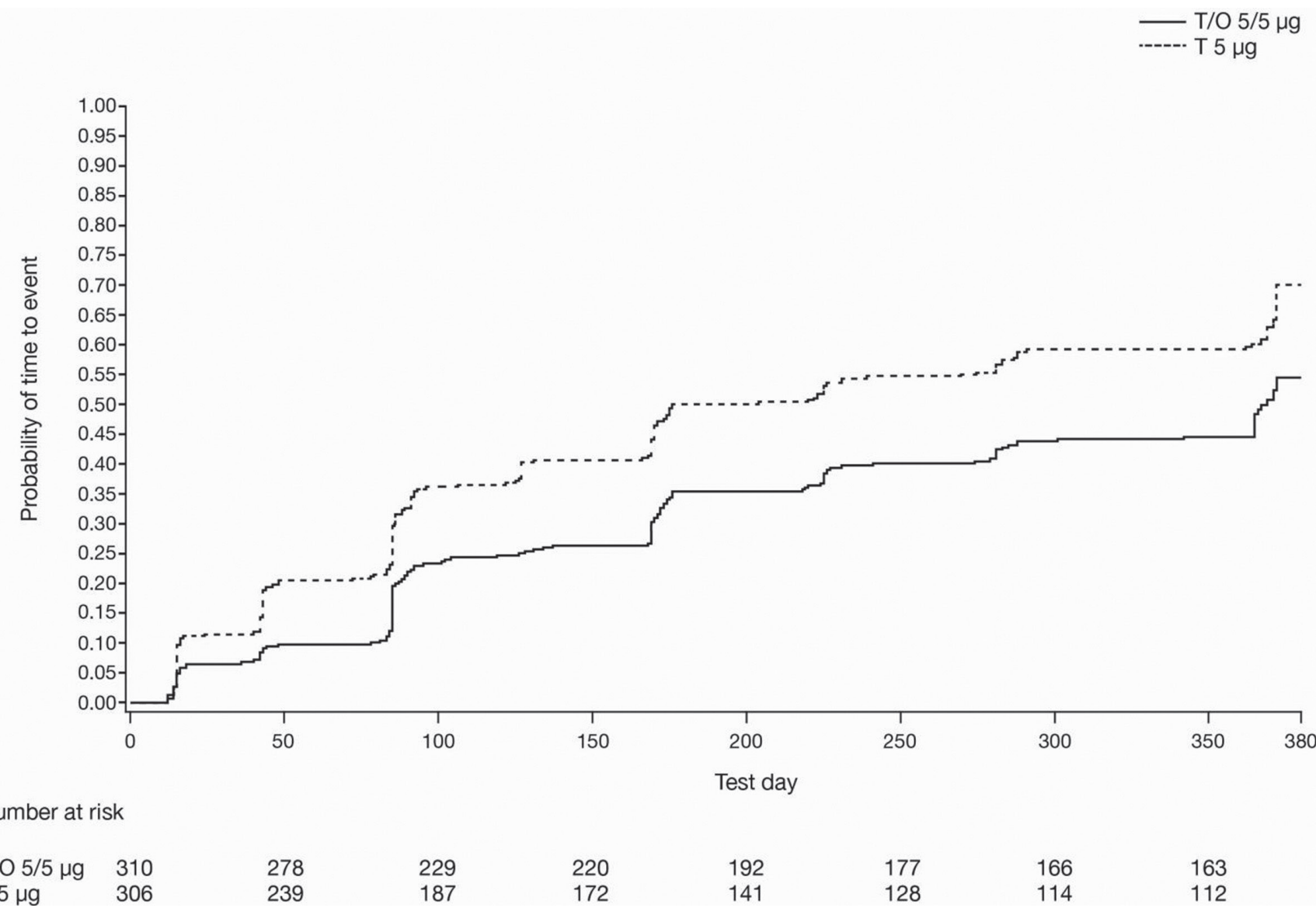

Abstract P294 Figure 1 Kaplan-Meier estimates of time to clinically significant event (decline from baseline $\mathrm{FEV}_{1}$ of $\geq 100 \mathrm{~mL}$; increase from baseline of $\geq 4$ units SGRQ total score; severe exacerbation; death) in patients with GOLD stage B COPD

clinically significant events in patients with GOLD stage B COPD.

Methods A total of 5162 patients were randomised to $\mathrm{O} 5 \mu \mathrm{g}$, $\mathrm{T} 2.5 \mu \mathrm{g}, \mathrm{T} 5 \mu \mathrm{g}, \mathrm{T} / \mathrm{O} 2.5 / 5 \mu \mathrm{g}$ or $\mathrm{T} / \mathrm{O} 5 / 5 \mu \mathrm{g}$ (delivered via Respimat inhaler) in two 52-week, parallel-group, double-blind studies (NCT01431274; NCT01431287). In this post hoc analysis of the combined TONADO ${ }^{\circledast}$ data, clinical deterioration was defined according to a composite end point: time to first decrease in trough forced expiratory volume in 1 second $\left(\mathrm{FEV}_{1}\right)$ from baseline of $\geq 100 \mathrm{~mL}$; increase in St George's Respiratory Questionnaire (SGRQ) total score from baseline of $\geq 4$ units; severe (hospitalised) exacerbation; or death. Only patients classified as GOLD stage B were included. Data are presented for comparisons of the licensed doses of T $5 \mu \mathrm{g}$ and T/O $5 / 5 \mu \mathrm{g}$.

Results 306 and 310 patients were included in this analysis in the $\mathrm{T} 5 \mu \mathrm{g}$ and $\mathrm{T} / \mathrm{O} 5 / 5 \mu \mathrm{g}$ treatment groups, respectively. Time to clinical deterioration was significantly longer with $\mathrm{T} / \mathrm{O} 5 / 5 \mu \mathrm{g}$ than T $5 \mu \mathrm{g}$ (25th percentile 128 versus 85 days; HR 0.650; 95\% CI: 0.524, 0.805; p < 0.0001) (Figure). Times to trough $\mathrm{FEV}_{1}$ decline and SGRQ increase were significantly longer with $\mathrm{T} / \mathrm{O} 5 / 5 \mu \mathrm{g}$ than T $5 \mu \mathrm{g}$ (226 versus 91 days and 369 versus 175 days, respectively). $25^{\text {th }}$ percentiles for time to severe exacerbation and time to death were not estimable due to low event rates. Conclusions In the TONADO ${ }^{\circledast}$ studies, T/O increased time to clinical deterioration compared to $\mathrm{T}$ alone in patients with GOLD stage $B$ disease. This suggests that, in this patient population, $\mathrm{T} / \mathrm{O}$ is more effective than $\mathrm{T}$ in preventing these significant events. Further studies are warranted to prospectively study this effect.

Funding Boehringer Ingelheim.

Please refer to page A272 for declarations of interest in relation to abstract P294.

\section{P295 EFFICACY AND SAFETY OF TIOTROPIUM/OLODATEROL IN PATIENTS WITH COPD BY ATS CATEGORY}

${ }^{1} \mathrm{~F}$ Maltais, ${ }^{2} \mathrm{E}$ Pizzichini, ${ }^{3} \mathrm{~L}$ Grönke, ${ }^{3} \mathrm{~F}$ Voß, ${ }^{4} \mathrm{E}$ Derom. ${ }^{1}$ Département de Médecine, Centre de Recherche, Institut Universitaire de Cardiologie et de Pneumologie de Québec, Québec, Canada; ${ }^{2}$ Department of Pulmonology, NUPAIVA (Asthma Research Centre), Universidade Federal de Santa Catarina, Santa Catarina, Brazil; ${ }^{3}$ Boehringer Ingelheim Pharma GmbH and Co. KG, Ingelheim, Germany; ${ }^{4}$ Department of Respiratory Medicine, Ghent University Hospital, Ghent, Belgium

\subsection{6/thoraxjnl-2016-209333.438}

Rationale The once-daily combination of tiotropium (T), a longacting muscarinic antagonist, and olodaterol $(\mathrm{O})$, a long-acting $\beta_{2}$-agonist, has demonstrated efficacy and safety in chronic obstructive pulmonary disease (COPD). ${ }^{1}$ Recently, it has been demonstrated that patients with milder disease (GOLD 2) have better bronchodilator responses compared to those with more severe disease. This post hoc analysis investigated whether the response to $\mathrm{T} / \mathrm{O}$ and to $\mathrm{T}$ alone is influenced by forced expiratory volume in 1 second $\left(\mathrm{FEV}_{1}\right)$ American Thoracic Society (ATS) category (mild, moderate or severe). 


\begin{tabular}{|c|c|c|c|c|}
\hline \multirow[b]{2}{*}{$\mu \mathrm{g}$} & \multicolumn{2}{|c|}{ Trough $\mathrm{FEV}_{1}$, L } & \multicolumn{2}{|c|}{$\mathrm{FEV}_{1} \mathrm{AUC}_{0-3,} \mathrm{~L}$} \\
\hline & $\mathrm{n}$ & Adjusted mean (SE) & $\mathrm{n}$ & Adjusted mean (SE) \\
\hline Mild & 351 & $0.058(0.011)$ & 353 & $0.152(0.011)$ \\
\hline T 5 & 338 & $0.141(0.012)^{*}$ & 340 & $0.275(0.011)^{*}$ \\
\hline \multicolumn{5}{|l|}{ T/0 5/5 } \\
\hline Moderate & 320 & $0.097(0.011)$ & 322 & $0.174(0.011)$ \\
\hline T 5 & 338 & $0.156(0.011)^{* *}$ & 339 & $0.282(0.011)^{*}$ \\
\hline \multicolumn{5}{|l|}{ T/0 5/5 } \\
\hline Severe & 347 & $0.088(0.009)$ & 351 & $0.131(0.009)$ \\
\hline T 5 & 341 & $0.123(0.009)^{* * *}$ & 344 & $0.227(0.009)^{*}$ \\
\hline T/0 5/5 & & & & \\
\hline
\end{tabular}

${ }^{*} \mathrm{p}<0.0001$ vs T $5 \mu \mathrm{g} ;{ }^{* *} \mathrm{p}<0.001$ vs T $5 \mu \mathrm{g} ;{ }^{* * *} \mathrm{p}<0.01$ vs T $5 \mu \mathrm{g}$

$\mathrm{SE}$, standard error

Methods In total, 5162 patients were randomised to $\mathrm{O} 5 \mu \mathrm{g}$, $\mathrm{T} 2.5 \mu \mathrm{g}$, T $5 \mu \mathrm{g}, \mathrm{T} / \mathrm{O} 2.5 / 5 \mu \mathrm{g}$ or T/O $5 / 5 \mu \mathrm{g}$ (via Respimat inhaler) in two 52-week, parallel-group, double-blind studies (TONADO $^{\circledast} 1$ and 2: NCT01431274; NCT01431287). This post hoc analysis focuses on the $\mathrm{T} 5 \mu \mathrm{g}$ and $\mathrm{T} / \mathrm{O} 5 / 5 \mu \mathrm{g}$ analyses. Primary efficacy end points were trough $\mathrm{FEV}_{1}$ response (ie, change from baseline) and $\mathrm{FEV}_{1}$ area under the curve from $0-3$ hours $\left(\mathrm{AUC}_{0-3}\right)$ response. Data are presented for patients by ATS category subgroups: mild (predicted $\mathrm{FEV}_{1} \geq 50 \%$ ), moderate (35 $\leq 50 \%)$ and severe $(<35 \%)$, using data pooled from both of the TONADO ${ }^{\circledast}$ studies.

Results In all disease-severity categories, the improvements in trough $\mathrm{FEV}_{1}$ and $\mathrm{FEV}_{1} \mathrm{AUC}_{0-3}$ were larger with $\mathrm{T} / \mathrm{O}$ compared to $\mathrm{T}$ alone. However, trough $\mathrm{FEV}_{1}$ and $\mathrm{FEV}_{1} \mathrm{AUC}_{0-3}$ responses were generally greater in patients with mild (T/O versus $\mathrm{T}$ : both $\mathrm{p}<0.0001)$ or moderate $(\mathrm{T} / \mathrm{O}$ versus $\mathrm{T}: \mathrm{p}<0.001$ and $\mathrm{p}<0.0001$, respectively) COPD versus those with severe COPD ( $\mathrm{T} / \mathrm{O}$ versus $\mathrm{T}: \mathrm{p}<0.01$ and $\mathrm{p}<0.0001$, respectively) at baseline (Table). Treatments were well tolerated across all ATS categories and similar responses were observed in both of the studies individually.

Conclusions These data build on the analysis of the GOLD 2 population from TONADO ${ }^{\circledast}$ and confirm that patients with mild to moderate disease derive greater benefits with $\mathrm{T} / \mathrm{O}$ than with $\mathrm{T}$. There was an overall trend towards greater lung-function improvement with $\mathrm{T} / \mathrm{O}$ or $\mathrm{T}$ alone in patients with mild/moderate versus severe airflow obstruction.

Funding Boehringer Ingelheim.

\section{REFERENCE}

1 Buhl R, et al. Eur Respir J 2015;45:969-979.

Please refer to page A273 for declarations of interest in relation to abstract P295.

\section{P296 EFFECT OF TIOTROPIUM/OLODATEROL THERAPY ON COPD EXACERBATIONS IN THE TONADO ${ }^{\circledR}$ STUDIES}

${ }^{1} \mathrm{E}$ Derom, ${ }^{2} \mathrm{M}$ Fležar, ${ }^{3} \mathrm{~L}$ Grönke, ${ }^{3} \mathrm{~F}$ VoB, ${ }^{4} \mathrm{R}$ Buhl. ${ }^{1}$ Ghent University Hospital, Ghent, Belgium; 'University Clinic of Respiratory and Allergic Diseases, Golnik, Slovenia; ${ }^{3}$ Boehringer Ingelheim Pharma GmbH and Co. KG, Ingelheim, Germany; ${ }^{4}$ Pulmonary Department, Mainz University Hospital, Mainz, Germany

\subsection{6/thoraxjnl-2016-209333.439}

Rationale The lung-function efficacy, symptomatic benefits and safety of combined tiotropium (T), a long-acting muscarinic antagonist, and olodaterol $(\mathrm{O})$, a long-acting $\beta_{2}$-agonist, for the treatment of COPD, was established in the year-long TONADO ${ }^{\oplus}$ studies (NCT01431274; NCT01431287). It is unknown if these benefits of $\mathrm{T} / \mathrm{O}$ translate into a reduction in COPD exacerbation rate.

Methods Two replicate, randomised, double-blind, parallel-group trials assessed T/O 2.5/5 $\mu \mathrm{g}$ and $\mathrm{T} / \mathrm{O} 5 / 5 \mu \mathrm{g}$ compared to the monocomponents T $5 \mu \mathrm{g}, \mathrm{T} 2.5 \mu \mathrm{g}$ and $\mathrm{O} 5 \mu \mathrm{g}$ (all delivered via Respimat ${ }^{\oplus}$ inhaler) in patients with moderate to very severe COPD. Primary end points included lung function (forced expiratory volume in 1 second $\left[\mathrm{FEV}_{1}\right]$ area under the curve from $0-3$ hours response, trough $\mathrm{FEV}_{1}$ response) and quality of life (SGRQ). Analysis of the number of exacerbations and time to exacerbation was pre-specified using data from the combined TONADO $^{\oplus}$ studies. We present data from the T/O and $\mathrm{T}$ treatment arms.

Results 4124 patients were evaluable for the $\mathrm{T} / \mathrm{O}$ and $\mathrm{T}$ treatment arms. Moderate or severe exacerbations occurred in $27.7 \%$ of patients with T/O $5 / 5 \mu \mathrm{g}, 25.8 \%$ of patients with T/O $2.5 / 5$ $\mu \mathrm{g}, 28.8 \%$ with T $5 \mu \mathrm{g}$ and $29.6 \%$ with T $2.5 \mu \mathrm{g}$. Severe exacerbations occurred in $5.9 \%$ of patients receiving $\mathrm{T} / \mathrm{O} 5 / 5 \mu \mathrm{g}, 4.5 \%$ receiving $\mathrm{T} / \mathrm{O} 2.5 / 5 \mu \mathrm{g}, 4.5 \%$ receiving $\mathrm{T} 5 \mu \mathrm{g}$ and $5.2 \%$ receiving $\mathrm{T} 2.5 \mu \mathrm{g}$. The treatment comparisons for any exacerbation and moderate/severe exacerbations were generally consistent between the two studies, except for a higher number of severe exacerbations with T/O $5 / 5 \mu$ in TONADO $^{\circledast} 1$ only (Table).

Conclusions Although there were fewer exacerbations overall with $\mathrm{T} / \mathrm{O} 2.5 / 5 \mu \mathrm{g}$ or $5 / 5 \mu \mathrm{g}$ compared to $\mathrm{T} 2.5 \mu \mathrm{g}$ or $5 \mu \mathrm{g}$, and a numerically longer time to first moderate/severe exacerbation,

\begin{tabular}{llll}
\multicolumn{2}{l}{ Abstract P296 Table 1} & Treatment & comparisons of time to first COPD exacerbation and first moderate/severe COPD exacerbation \\
\hline Treatment comparison, $\boldsymbol{\mu g}$ & Time to first COPD exacerbation & Time to first moderate/severe COPD exacerbation & Time to first severe COPD exacerbation \\
\hline T/0 $5 / 5-$ & 0.938 & 0.931 & 1.279 \\
T 5 & $(0.801,1.099)$ & $(0.791,1.095)$ & $(0.874,1.871)$ \\
T/O $5 / 5-$ & 0.897 & 0.901 & 1.105 \\
T 2.5 & $(0.767,1.049)$ & $(0.767,1.059)$ & $(0.766,1.593)$ \\
T/O $2.5 / 5-$ & 0.819 & 0.822 & 0.817 \\
T 2.5 & $(0.698,0.960)^{*}$ & $(0.697,0.969)^{*}$ & $(0.551,1.210)$ \\
T/O $2.5 / 5-$ & 0.857 & 0.850 & 0.948 \\
T 5 & $(0.730,1.007)$ & $(0.720,1.003)$ & $(0.632,1.424)$ \\
T/0 $5 / 5-$ & 1.095 & 1.096 & 1.352 \\
T/0 $2.5 / 5$ & $(0.931,1.288)$ & $(0.927,1.295)$ & $(0.922,1.983)$ \\
\hline
\end{tabular}

Hazard ratio (95\% confidence interval) $p<0.05$ 